\title{
Application of Reverse Logistics Management in Solid Waste
}

\author{
Disposal in Handan City \\ Jie Wang * \\ Ministry of Education Key Laboratory for Urban Transportation Complex System \\ Theory and Technology, Beijing Jiao Tong University, Beijing 100044, China \\ *Corresponding author: Jie Wang, 15125788@bjtu.edu.cn
}

\begin{abstract}
In order to effectively solve the problem of waste disposal by using reverse logistics management, this paper analyses the current situation and problem of the Municipal waste emissions in Handan. Through the questionnaire survey, data collection and survey, we find that there are so many problems in reverse logistics, such as the weak awareness of reverse logistics, the high cost of circulation, low degree of the information technology. So reverse logistics management is applied to the urban waste treatment, we proposed to constructing an information platform and offering information technology support. What's more, we introduce the third party reverse logistics management to solve urban waste which have great significance.
\end{abstract}

Keywords: reverse logistics, solid waste, Handan City, information, network

\section{Introduction}

It is estimated that municipal waste is produced about 1.5 million tons in China each year, waste generation reached 1-2 kg Per person. At present, according to the related data statistics, there are about 2100 million tons of urban solid waste, which will be increased about $10 \%$ year by year. ${ }^{1}$ The growing number of the municipal solid waste has become obstacles to China's economic development, so it is important to carry out effective resource management to solve municipal solid waste.

The landfill is the main way of solid waste treatment in most cities, but this way will occupy land area ,cause soil and groundwater pollution,meanwhile it may waste a lot of recyclable resources, such as waste paper, scrap metal, rubber etc.Incineration method is a high temperature processing of city solid wastes,it has the following advantages: shorter processing time, small occupied area and etc, but the investment cost is relatively high, after burning, the tail gas will cause the Second pollution. Solid waste is not easy to concentrate to deal with. ${ }^{2}$

Reverse logistics are the processing of materials flow including semi-finished products, finished goods and related information from the consumer side flow back to 
the initial point to plan, management and control process (Roger D.S et al. ${ }^{3}$ ) . This process is consistent with the concept of pursuing sustainable development in China, which will concentrate on solid waste to transport and classify. So it is important to apply reverse logistics management to solid waste efficiently.

\section{Experimental}

\subsection{Test site}

We take Handan city as the research object to analyse the status of solid waste.

Handan is a typical city of heavy industry, whose advantage lies in the development of iron,steel,electricity and coal, but just for this it brings pressure of environmental problems.So it is significant to apply the reverse logistics management in Handan.

\subsection{Data collection}

Data were collected from Hebei provincial environmental protection department, Handan City Environmental Protection Bureau, online searching, site visits and questionnaire to perform statistical analysis.

\subsubsection{These solid waste emissions data were collected from various sites}

From Table1-2, we can be informed that most of the solid waste in Handan are industrial solid waste and municipal solid waste (3505.02 Million tons, 62.12 Million tons). Municipal solid waste is disposed by the landfill and medical waste mainly by incineration. There are a lot of problems in the way of recycling. The comprehensive utilization rate of general solid waste and hazardous solid waste is very low as shown in Fig.1, Fig.2, so we can know that reverse logistics lack sufficient attention.

Table 1-Industrial waste investigation in Handan 2013

\begin{tabular}{|l|l|l|l|l|l|}
\hline Types of solid waste & $\begin{array}{l}\text { Production } \\
\text { quantity }\end{array}$ & $\begin{array}{l}\text { Comprehensive } \\
\text { utilization }\end{array}$ & $\begin{array}{l}\text { Disposal } \\
\text { rate }\end{array}$ & $\begin{array}{l}\text { Storage } \\
\text { rate }\end{array}$ & $\begin{array}{l}\text { Solid } \\
\text { emissions }\end{array}$ \\
\hline $\begin{array}{l}\text { Industrial solid } \\
\text { waste(Million tons })\end{array}$ & 3505.02 & 3027.69 & 8.44 & 468.89 & 0.19 \\
\hline $\begin{array}{l}\text { Industrial hazardous } \\
\text { waste }\end{array}$ & 918.2 & 9.44 & 787.9 & 18.88 & 0 \\
\hline
\end{tabular}

Table 2- Domestic waste and medical waste in 2013

\begin{tabular}{|l|l|l|l|l|}
\hline Types of solid waste & Production quantity & Disposal quantity & Disposal rate & Disposal method \\
\hline MSW (Million tons) & 62.12 & 62.12 & $100 \%$ & security landfill \\
\hline Domestic waste & 1527.69 & 1527.69 & $100 \%$ & Incineration \\
\hline
\end{tabular}




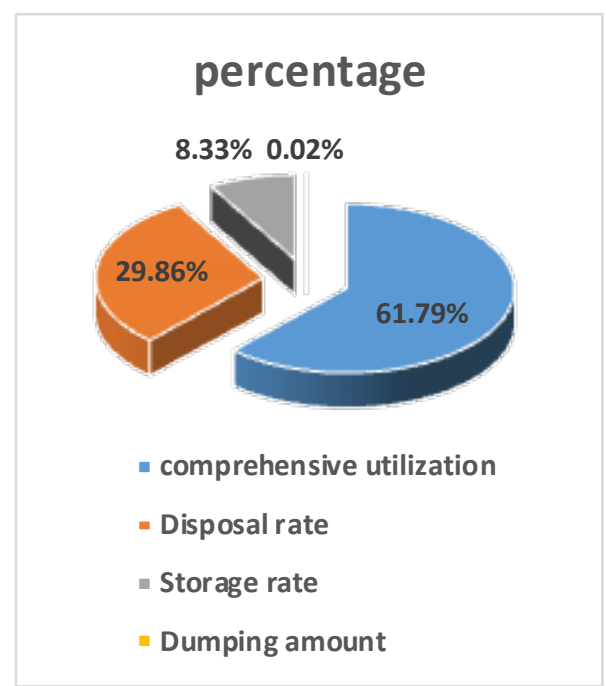

Fig.1-General solid waste

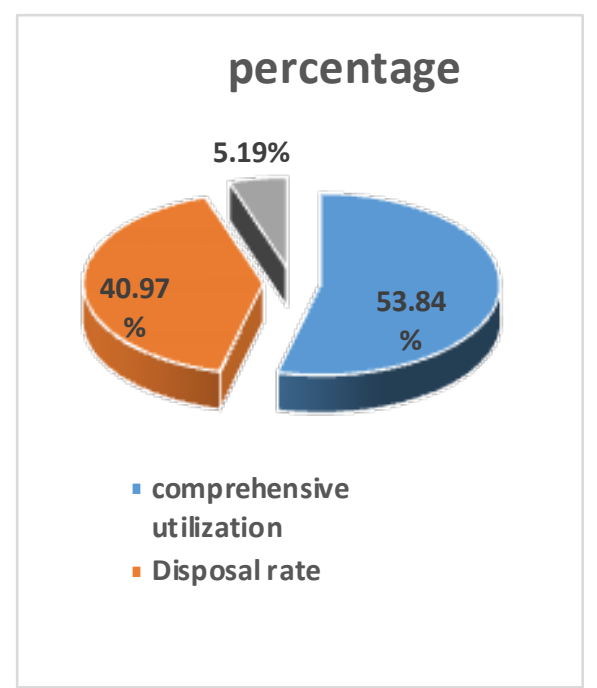

Fig.2-Hazardous solid waste

2.2.2we make a questionnaire to further investigate the causes of the above problems, The questionnaire issued a total of 300 which is for Handan City public and enterprises. The statistics results are mainly about understanding and acceptance of the public to reverse logistics and the reasons why not accept the reverse logistics.
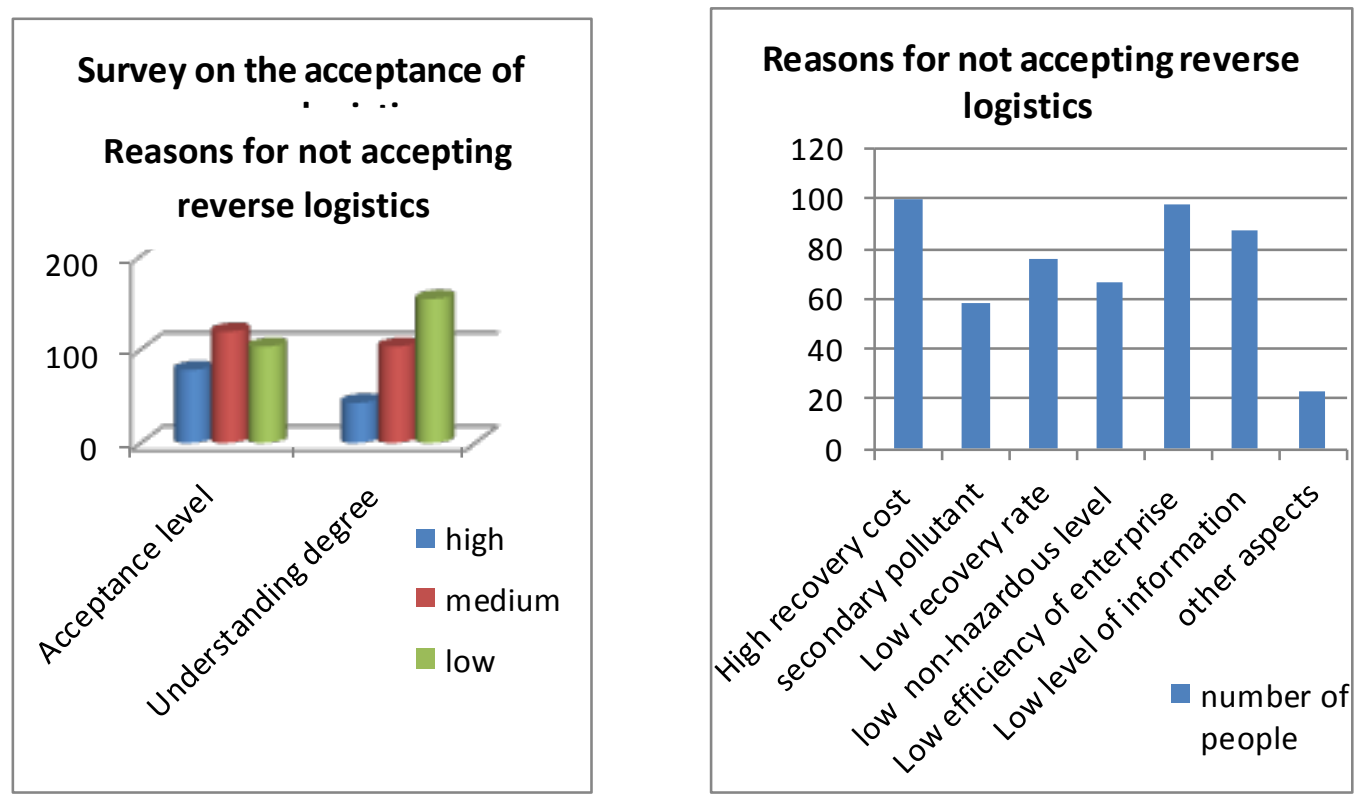

Fig.3- the acceptance of reverse logistics Fig.4- Reasons for not accepting reverse logistics

\section{Results}

Through the data analysis above, we can find that there are some problems in the development of reverse logistics in Handan.

\subsection{The weak awareness of reverse logistics}

From the Fig3, we can see that the number of people of low understanding and acceptance level $(103,154)$ is relatively high. According to the relevant investigation, 
some enterprises think that the reverse logistics will bring the burden, information technology and logistics business process will be more complicated. For the general public, the consumers pay more attention to the origin of products, have scarcely acceptance of the reused product which comes from the origin of reverse logistics.

\subsection{The higher cost of circulation in the process of reverse logistics}

From the Fig4, we can figure that most people (1/3) who do not accept the logistics consider that the cost is too high. The first reason is that the forward logistics and reverse logistics belong to different departments and separate chain, the management processes are relatively cumbersome, with low efficiency and high cost. Secondly, forward logistics set the level of economic benefits as an index, while reverse logistics pay more attention on the environmental benefits. More and more enterprises think that the reverse logistics have lower economic benefit and higher investment, which will make available resources get less effective recycling.

\subsection{The low degree of the information technology of reverse logistics}

From the statistics in Fig1 Fig2, and the results of questionnaire survey in the Fig4, we can see the rate of utilization and disposal of Hazardous solid waste $(53.8 \%, 40.9 \%)$ is not high, which attributed to the low level of information and technique. According to our investigation which related to most of the enterprises, the current information technology can`t keep up with the development of reverse logistics. Recycling technology and harmless treatment technology needs to be improved in logistics.

\section{Discussion}

Based on the analyses above, some feasible suggestions are put forward:

\subsection{The establishment of reverse logistics center}

According to the survey, the largest enterprise of the third party logistics company in Handan is Hanyun group, which ranks in fifty among the 100 logistics enterprises. Compared with developed countries, the development level of the logistics industry is not high in Handan. There are so many small and medium sized logistics companies but less reverse logistics center in Handan. Related enterprises can deliver it`s logistics business which they are not good at to the more professional third party reverse logistics. ${ }^{4}$ Through the joint, mergers and acquisitions, we can encourage the logistics enterprises to develop the large and functional reverse logistics center shown in Fig.5.Compared with the small businesses, professional and scaled reverse logistics center can greatly reduce logistics costs and improve market competitiveness. 


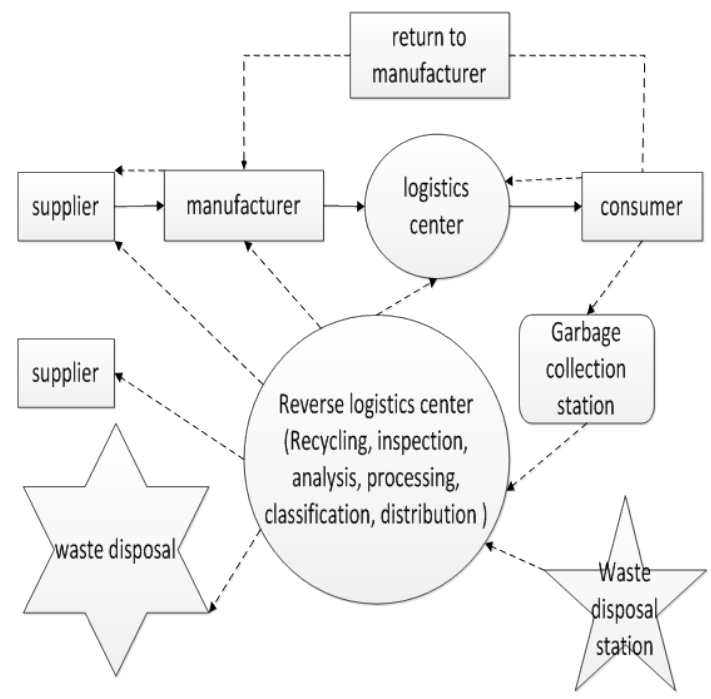

Fig.5-network of reverse logistics center

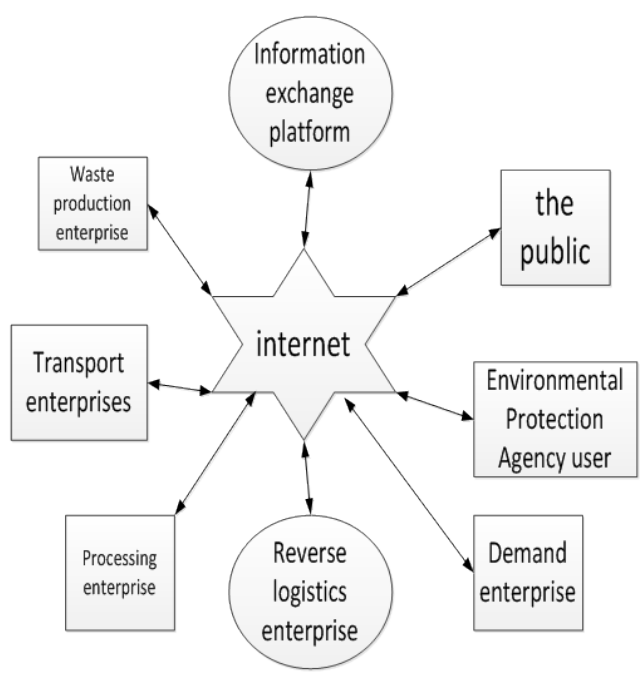

Fig.6- Reverse logistics information platform

\subsection{Constructing the information platform of reverse logistics in Handan}

According to the analysis, we know that the high cost of reverse logistics is because of the forward logistics and reverse logistics in two different chains, which have not formed a whole system. The information platform can well get mutual resources utilized and shared between the integration of the resource companies shown in Fig.6, it can also integrate the government information, enterprise information and logistics information to ensure the vitality of platform and completeness of information.

\subsubsection{Operation of information platform}

The public, processing enterprises, and reverse logistics enterprises collects solid waste in different ways, they can classify solid waste based on the recovery position, recovery time and other information about the reverse activity. The solid waste is transported to a recycling center station, we can use all the information to sort and dismantle them, it will return products into parts, this process could be used for the recycling of waste household appliances. The parts information is input into the system, we can determine its recovery methods including reusing, remanufacturing, disposal. Reverse logistics enterprises can also carry out the warehouse management according to the spare parts enterprises, information will provide by information platform, the production plan can schedule manufacture according to the number of parts and information platform. Government agencies take a regulatory role as well.

\subsubsection{Information platform technology support}

System integration technology. Based on this technology, information platform integrates users, information and business process to form an integrated system. All participating users will have a unified operation interface and improve the efficiency of the system. The system integration technology can organize disorder flow data into information flow, and then we can make it into information service.

Internet of Things (IOT) technology. It is most widely used in the field of logistics; its 
core technology is RFID which can automatically transmit the data to the information platform through wireless data communication network, information platform can realize the data exchange and data integration, finally achieve effective management of reverse logistics. IOT technology can be closely combined with GPS, GIS and MIS, which can provide effective support in transportation planning, storage management and recycling network planning.

Big data technology. Reverse logistics will produce a large number of data information. Information platform can use the big data technology to gather information, sort out information, manage and process information from a large number of data information to provide accurate information services, so that it can help reverse logistics business more actively participate in decision-making.

\subsection{Strengthen the responsibility of production and distribution}

In order to strengthen the development of reverse logistics in Handan, we can promote the cooperation in various productive enterprises, circulation enterprises and recycling enterprises, the available resources and waste can be effectively reused and turned into treasure. For heavy industry in the Handan City, all the relevant production and circulation enterprises cooperate with each other, waste elimination is just another Party's products and raw materials, the cost can be lower. Resource recycling system is combined by steel mills, power plants, cement plants, residential areas, building materials factory, electronics industry, fertilizer plant and so on.as shown in Fig.7.

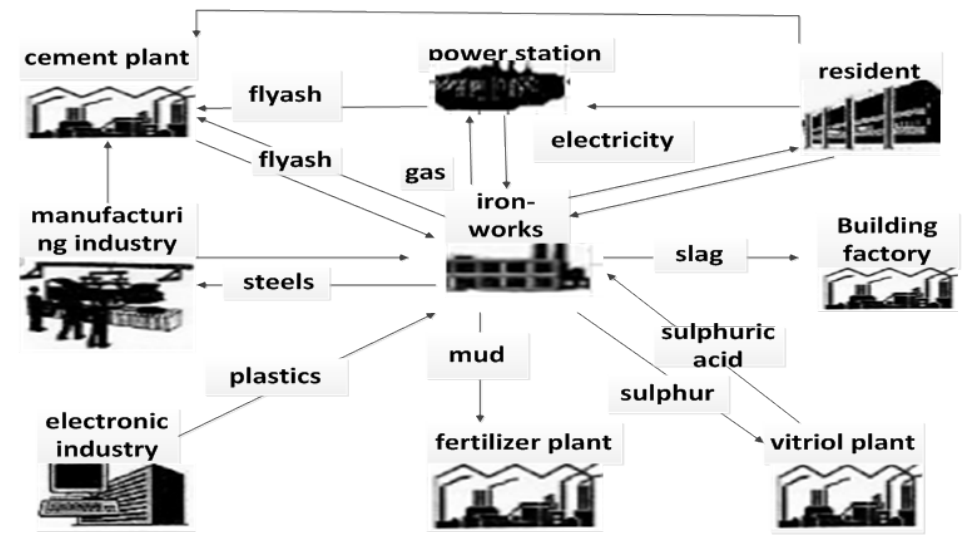

Fig.7- Enterprise operation network

\section{Conclusion}

Theoretical study on the reverse logistics has carried out for 10 years in foreign countries, in the domestic it is only in recent years. It is important to recycle the waste materials and reduce the pollution of the environment, which has become the focus of attention of the academic circles and the business community. Overall, research in this field is still in an initial stage, there are still many problems need further study. 


\section{Reference}

1. Song Yazhi., Present situation and Countermeasures of municipal solid waste in China. Coal engineering, 2002, (3):39-40.

2. Fan,F.,Application of reverse logistics management in municipal solid waste. Modern enterprise culture, 2009, (5):111-112.

3. Roger D.S., Tibben-Lembke R.S. Going backwords:reverse logistics trends and Practices. Reverse Logistics Executive Council, Pittsburg, PA.1999.

4. Wei W.H., Xiong, M.Q., The improvement of reverse logistics system of solid waste. Urban management and science technology, 2014 (6):38-40.

5. Li,Z.H., Research on the construction of reverse logistics network based on fuzzy random environment. Logistics engineering and management, 2015,37 (2): 18-19. 